The onset is slow with a few lesions appearing on the upper trunk, scalp, or face so that seborrhoeic dermatitis is often diagnosed. Sometimes the rash covers the entire body surface in an exfoliative dermatitis. Histological examination of a lesion less than 24 hours old shows blister formation at a higher level in the epidermis than is found in pemphigus vulgaris. The thin roof accounts for the fragility of the blister and explains why intact lesions are so rarely seen.

Over the past five years 160 patients from the rheumatology departments of Stoke Mandeville Hospital, Aylesbury, and the Nuffield Orthopaedic Hospital, Oxford, have been treated with penicillamine, but only 104 have taken it for over six months. The seven patients reported here developed an itchy, non-specific rash after taking penicillamine in moderate doses for six to 12 months. Blisters were seen at the onset of the eruption in only two patients, whereas scaly plaques were prominent in the others, who were thought to have the "late penicillamine rash." In three of these pemphigus foliaceus was diagnosed when blisters became apparent. Exposure to sunlight often aggravates this condition and possibly precipitated the exacerbation in cases 2 and 4 . The findings suggest that the "late rash" recorded by rheumatologists is a mild transient form of pemphigus foliaceus.

The cause of pemphigus is unknown, although the presence of circulating antibodies to intercellular epidermal material in almost all cases suggests an immune mechanism. Pemphigus is often associated with immune disorders such as myasthenia gravis and lupus erythematosus, but there have been no reports of a significant relation between pemphigus and rheumatoid arthritis in the absence of penicillamine therapy. The capacity of penicillamine's sulphydryl group to bind to or cleave protein might alter epidermal intercellular cement substance, a proteoaminoglycan, with subsequent antibody formation. Reports of other drugs causing pemphigus are rare, but rifampicin, phenylbutazone, and Irgapyrin have been held responsible. ${ }^{14} 15$

Pemphigus foliaceus tends to have a prolonged course and may be fatal. The persistence of the rash in cases 1 and 2, 12 and 23 months after stopping penicillamine is therefore worrying. Although pemphigus foliaceus is less aggressive than pemphigus vulgaris, up to $60 \%$ of patients died of this disease before the introduction of corticosteroids; spontaneous remission occurred in about half of the survivors. $^{16}$ The prognosis has improved but $120-200 \mathrm{mg}$ prednisolone daily may be required to control severe cases followed by maintenance doses usually over $30 \mathrm{mg} /$ day. Many believe that even higher doses (up to $240 \mathrm{mg}$ prednisolone daily) given for six to eight weeks are more likely to induce full remission, and cases 1 and 2 might have benefited from this more intensive regimen. Localised pemphigus foliaceus, as found in cases 3 and 4 , is usually treated conservatively and may respond to topical corticosteroids alone.

Serum epithelial antibody titres in spontaneously occurring forms of pemphigus usually correlate well with the activity of the disease. In our patients, however, and those of Hewitt $e t$ al, ${ }^{11}$ levels were low even though some patients had extensive lesions. Also of interest was the discovery of circulating epithelial antibody in case 4 about nine months after the rash had disappeared and penicillamine had been reintroduced. Further investigation is therefore required to explain these anomalies and to determine whether the antibody is found in the blood before the onset of the eruption. ${ }^{17}$ Serial serum antibody estimations might be helpful in managing and preventing this serious disease.

We thank Dr John Morton, Dr Margaret M Pickles, and Miss Jean Turner, department of immunopathology, and Dr I C M MacLennan, Mr J Clarke, and Mrs Joy Bull, Nuffield department of clinical medicine, Radcliffe Infirmary, Oxford, for their help. Thanks are also due to Dr C L Greenbury and $\mathrm{Dr}$ Joan Rivett of the department of pathology, Stoke Mandeville Hospital, Aylesbury.

1 Walshe, J M, Postgraduate Medical fournal, 1968, 44, Suppl, p 6.

2 Scheinberg, I H, Postgraduate Medical fournal, 1968, 44, Suppl, p 11.

${ }^{3}$ Crawhall, J C, and Watts, R W E, Postgraduate Medical fournal, 1968, 44, Suppl, p 8.

${ }^{4}$ Huskisson, E C, and Mowat, A G, Clinics in Rheumatic Diseases, 1975, 1, 319.

${ }^{5}$ Katz, R, Archives of Dermatology, 1967, 95, 196.

${ }^{6}$ Beer, W E, and Cooke, K B, British fournal of Dermatology, 1967, 79, 123.

7 Pass, D, et al, Archives of Dermatology, 1973, 108, 713.

${ }^{8}$ Lancet, 1975, 1, 1123.

${ }^{9}$ Degos, M M R, et al, Bulletin de la Société Française de Dermatologie et de Syphiligraphie, 1969, 76, 751.

${ }^{10}$ Hewitt, J, et al, Annales de Médicine Interne, 1971, 122, 1003.

${ }^{11}$ Hewitt, J, Benveniste, M, and Lessana-Leibowitch, M, British Medical fournal, $1975, \mathbf{3}, 371$.
12 Cairns, R J, Proceedings of the Royal Society of Medicine, 1976, 69, 384.

${ }^{13}$ Rook, A, Wilkinson, D S, and Ebling, F J G, Textbook of Dermatology, 2nd edn. Oxford, Blackwell Scientific Publications, 1972.

14 Gange, $\mathrm{R}$ W, et al, submitted for publication.

15 Beutner, E H, Chorzelski, T P, and Jordan, R E, Autosensitisation in Pemphigus and Bullous Pemphigoid. Springfield, Illinois, Charles C Thomas, 1970.

16 Perry, H O, and Brunsting, L A, Archives of Dermatology, 1965, 91, 10.

17 Benveniste, M, et al, La Nouvelle Presse Médicale, 1975, 4, 3125.

Department of Dermatology, Slade Hospital, Headington, Oxford

R A MARSDEN, MRCP, senior registrar

T J RYAN, FRCP, consultant dermatologist

Department of Pathology, Radcliffe Infirmary, Oxford

R I VANHEGAN, BM, DPHIL, lecturer in pathology

Department of Dermatology, Royal Buckinghamshire Hospital, Aylesbury, Bucks

MARGARET WALSHE, FRCP, consultant dermatologist

Oxford Regional Rheumatic Disease Research Centre, Stoke Mandeville Hospital, Aylesbury, Bucks

HILARY HILL, FRCPED, medical assistant

Department of Rheumatology, Nuffield Orthopaedic Centre, Headington, Oxford

A G MOWAT, FRCP ED, consultant rheumatologist

\section{Prazosin treatment complicated by acute febrile polyarthritis}

Prazosin (Hypovase) is a recently introduced hypotensive agent, which is said to act peripherally by direct vasodilatation. ${ }^{1}$ Apart from collapse due to postural hypotension on starting treatment, ${ }^{2}$ side effects have been trivial. We draw attention here to a further possible complication of prazosin treatment.

\section{Case report}

In 1969 a 32-year-old man developed intermittent claudication of the right calf. No pulses could be felt below the femoral artery in the right leg. An aortogram showed complete occlusion of the right popliteal artery. Two years later he was reinvestigated after developing a left popliteal artery aneurism. He had bruits over both subclavian and carotid arteries. The right leg pulses were still absent. His erythrocyte sedimentation rate was $30 \mathrm{~mm}$ in $1 \mathrm{~h}$. Aortography showed, in addition to the aneurism, multiple stenoses in the head and arm vessels, left renal artery stenosis, and right popliteal artery occlusion. The aneurism was excised and examined histologically. No diagnostic pathological change was seen. A muscle biopsy specimen was normal. The patient remained well until six years later, when he was found to be hypertensive (blood pressure $180 / 120 \mathrm{~mm} \mathrm{Hg}$ ). An intravenous pyelogram and radioactive renograph confirmed the diagnosis of renal artery stenosis.

Treatment-He was started on prazosin $2 \mathrm{mg}$ three times a day, and his blood pressure was controlled.

Adverse effects-Ten weeks later he began to complain of "flu-like" symptoms with soreness of the throat associated with shivering and sweating. He developed an ache in the neck and pain in the right groin and was admitted to hospital. On examination he was febrile $\left(40^{\circ} \mathrm{C}\right)$. There was no lymphadenopathy or rash. The peripheral pulses were unchanged. His blood pressure was $180 / 110 \mathrm{~mm} \mathrm{Hg}$. Right hip and neck movements were full The prazosin was stopped and by the next morning his temperature was normal. Twenty-four hours later he developed acute arthritis of the right elbow and both knees with a large effusion into the right elbow joint. This arthritis settled within 24 hours with aspirin treatment. On admission he had a neutrophil leucocytosis (white cell count $15 \times 10^{9} / 1\left(15000 / \mathrm{mm}^{3}\right)$ ) and a plasma viscosity of 2.00 centipoise. Urine examination, blood urea and electrolytes, liver function tests, and blood lipids were normal. The serum urate concentration was normal and latex fixation test and test for antinuclear factor gave negative results. Blood cultures grew no organisms, and antibody titres against brucella and rickettsia were normal. The Wassermann reaction was negative. Radiographs of the chest and affected joints showed no abnormalities.

The patient was well when seen again two weeks after discharge and his prazosin was restarted. Three days later his symptoms recurred and he 
developed acute arthritis of the right wrist. The illness rapidly resolved when prazosin was stopped, and the patient has subsequently remained well.

\section{Comment}

Acute febrile polyarthritis developed after prazosin was started and resolved when it was stopped, only to recur on reintroduction. The nature of the patient's underlying vascular disease remains unclear but it has been quiescent for seven years. Serum sickness-like illnesses and systemic lupus erythematosus ${ }^{3}$ are associated with drug therapy. Notable among these is the illness caused by hydrallazine, ${ }^{4}$ another peripherally acting vasodilator used as a hypotensive agent. These syndromes are either the result of the pharmacological properties of the drug or, more commonly, allergic in origin. ${ }^{5}$ An allergic reaction seems more likely in our case. There was a long delay between starting the drug and the onset of symptoms. The onset was associated with leucocytosis and raised plasma viscosity, and symptoms recurred rapidly when prazosin was restarted.

1 Drugs and Therapeutic Bulletin, 1975, 13, 55.

2 Committee on the Safety of Medicines, Adverse Reaction Series No 12 London, HMSO, 1975.

${ }^{3}$ British Medical fournal, 1970, 2, 192.

${ }^{4}$ Condemi, J J, et al, New England fournal of Medicine, 1967, 276, 486.

${ }^{5}$ Alarcon-Segovia, D, Drugs, 1976, 12, 69.

Bristol Royal Infirmary, Bristol BS2 8HW

$S$ A CAIRNS, BSC, MRCP, medical registrar (now tutor in medicine, Manchester Royal Infirmary, Manchester)

$S$ C JORDAN, FRCP, consultant cardiologist

\section{SHORT REPORTS}

\section{Sodium repletion and beta-adrenergic blockade in treatment of salt depletion with accelerated hypertension}

The long historical association between salt and hypertension and the concept that the extracellular fluid volume is an important determinant of blood pressure have led to an emphasis on the role of excess salt in hypertension. The contrasting state of salt depletion is therefore not usually recognised as part of the hypertensive process. We have recently seen a patient with accelerated hypertension with severe salt depletion who was treated by combining hypotensive therapy with sodium repletion.

\section{Case report}

The patient, a previously healthy man aged 60 years, developed muscle aching, thirst, weight loss, and faintness when standing in January 1976 . He was admitted to hospital and found to be clinically dehydrated, with a blood pressure of $260 / 150 \mathrm{~mm} \mathrm{Hg}$ supine and $150 / 120 \mathrm{~mm} \mathrm{Hg}$ standing and grade 4 retinopathy. Plasma sodium was $126 \mathrm{mmol}(\mathrm{mEq}) / 1$, potassium $3.0 \mathrm{mmol}$ $(\mathrm{mEq}) / 1$, bicarbonate $35.0 \mathrm{mmol}(\mathrm{mEq}) / \mathrm{l}$, and creatinine clearance $42 \mathrm{ml} / \mathrm{min}$. Plasma renin activity was $20.4 \mu \mathrm{g} / \mathrm{l} / \mathrm{h}$ (normal $2-10 \mu \mathrm{g} / \mathrm{l} / \mathrm{h}$ ), plasma argininevasopressin 7.2 ng/1 (normal 0.35-0.95 ng/1), and 24-hour urinary aldosterone excretion $76 \mathrm{nmol}(27 \mu \mathrm{g})$ (normal 10-60 nmol (3.6-21.6 $\mu \mathrm{g})$ ). An intravenous urogram showed a non-functioning left kidney and renal arteriography showed a totally occluded left main renal artery. The angiotensin-II blocking drug saralasin (1-sar-8-ala-angiotensin II) was given in an intravenous bolus of $10 \mathrm{mg}$, and the blood pressure fell rapidly from $220 / 130 \mathrm{~mm} \mathrm{Hg}$ to $76 / 60$ $\mathrm{mm} \mathrm{Hg}$, returning to $160 / 80$ after 10 minutes.

Treatment was then begun with oxprenolol $40 \mathrm{mg}$ twice a day, Slow-K 64 $\mathrm{mmol} / \mathrm{day}$, and Slow-Na $60 \mathrm{mmol} /$ day. There was good early blood pressure control and a progressive rise in body weight and plasma sodium (see figure). The plasma potassium rose to $3.8 \mathrm{mmol} / 1$ and plasma arginine-vasopressin fell to $1.3 \mathrm{ng} / 1$. Between 17 and 24 March the dietary intake of sodium and potassium was fixed at $100 \mathrm{mmol} /$ day and $80 \mathrm{mmol} /$ day respectively, and there was no evidence of renal sodium loss (see figure). The blood pressure was eventually well controlled with the addition of prazosin, and remained so at six months.

\section{Comment}

The evidence for salt and water depletion in this patient was strong, and the rapid rise in body weight in response to treatment, paralleled by a rise in plasma sodium, could be satisfactorily explained only by fluid repletion.

Salt depletion is not generally considered as a possibility in severe hypertension, although Barraclough drew attention to it in a case report. ${ }^{1}$ Recent observations on renal hypertension in rats have shown that the accelerated phase is associated with the development of negative sodium balance and is transiently reversed by a high salt intake. ${ }^{2}$ The mechanism of this salt loss is uncertain, but it is possibly 